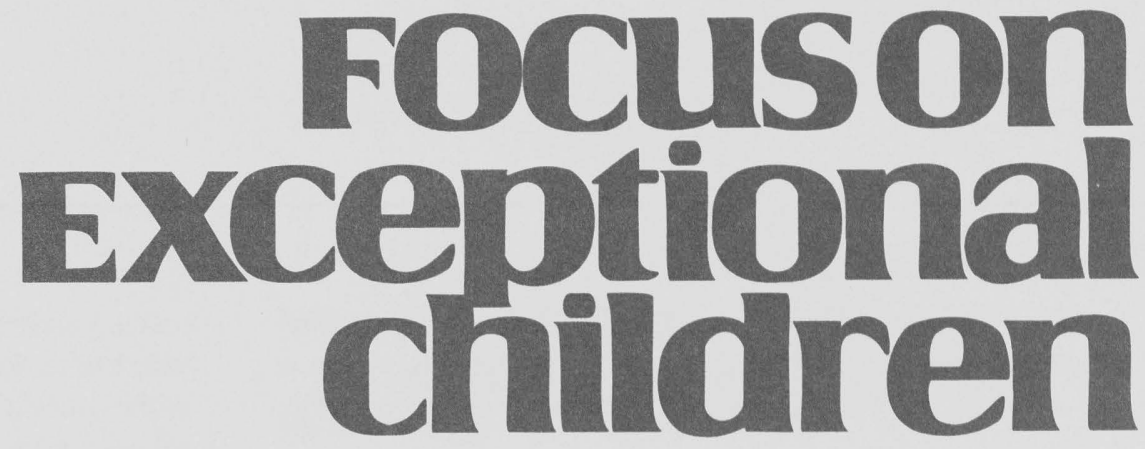

\title{
Best Academic Practices for Inclusive Classrooms
}

\author{
Margaret E. King-Sears
}

Concerning the title of this article: What is meant by "best?" Best means the finest, the greatest, the highest. "Best" for whom? Effective inclusion is best for everyone, not just students with disabilities. "Academic" practices toward what type of goal? Is the academic goal for a given student in the cognitive, affective, or psychomotor domain of learning? For example, a student with a learning disability may be working on cognitive IEP goals that emphasize reading and writing skills. A student with emotional or behavioral disorders may have affective IEP goals that emphasize ways to deal effectively with frustration. If a student with severe cognitive disabilities has affective IEP goals related to communicating during social situations, is the communication considered a cognitive area, or even a psychomotor area, for that student? A student with a physical disability may have psychomotor IEP goals that relate to reaching, manipulating, and movement. For each of these students, academics can encompass any of the domains of learning. Academic practices, therefore, are not confined to traditional content achievement areas such as reading, mathematics, and science.

Conversely, are there best academic practices for exclusive, or segregated, settings? Baker (1994) contends that servicing students in separate environments came about through measurements that indicated a student was not successful in the mass educational system of the times, and not as a result of measures comparing students' success in noninclusive educational practices to inclusive ones. Similarly, Sobsey and Dreimanis (1993) note that a segregated service delivery model did not develop as a result of empirical research or evaluation.

More recently, court decisions have placed the burden of proof on school systems to provide data that describe students' performance in inclusive environments with supplementary aids and services prior to removing students from these environments to more segregated ones (Yell, 1995). Baker concludes that current evidence that does compare students' achievement in integrated to segregated environments does not support the use of noninclusive environments for the education of students with disabilities.

A mistaken impression of inclusion is that special education is not needed. The fallacy is that if more students with disabilities spend more time in general education classrooms, the numbers of students who need specialized services diminish such that the quantity of students for a special educator's caseload eliminates the need for as many special education teachers. On the contrary, the need for specialized services and special educators is not re-

Dr. King-Sears is associate professor, Department of Special Education, Johns Hopkins University; project director for two teacher preparation grants from OSERS focusing on enhancing skills of educators from all disciplines for inclusion; and coordinator of Inclusion and Mild/Moderate Disabilities programs at Johns Hopkins. 
duced when inclusion occurs. After reviewing empirical research about the effects of inclusion on students with and without disabilities, Sobsey and Dreimanis (1993) conclude:

\begin{abstract}
Research to date leaves little doubt that the vast majority of students with intellectual disabilities do better in integrated classrooms rather than special education programs. This finding should not be interpreted as implying that the total withdrawal of special supports and services would be in the best interests of students with intellectual disabilities. It is only the delivery of special education services in segregated settings that is called into question-not the need for individualized and intensive education. (p. 10)
\end{abstract}

"Inclusion" as a term means different things to different people. For purposes of this article, I use a definition from York, Doyle, and Kronberg (1992): Inclusion is students with disabilities (a) attending the same schools as siblings and neighbors, (b) being in general education classrooms with chronological age-appropriate classmates, (c) having individ-

\title{
Focuson
Exceptional children
}

ISSN 0015-511X

FOCUS ON EXCEPTIONAL CHILDREN (USPS 203-360) is published monthly except June, July, and August as a service to teachers, special educators, curriculum specialists, administrators, and those concerned with the special education of exceptional children. This publication is annotated and indexed by the ERIC Clearinghouse on Handicapped and Gifted Children for publication in the monthly Current Index to Journals in Education (CIJE) and the quarterly index, Exceptional Children Education Resources (ECER). The full text of Focus on Exceptional Children is also available in the electronic versions of the Education Index. It is also available in microfilm from Xerox University Microfilms, Ann Arbor, MI. Subscription rates: Individual, $\$ 30$ per year; institutions, \$40 per year. Copyright (C) 1997, Love Publishing Company. All rights reserved. Reproduction in whole or part without written permission is prohibited. Printed in the United States of America. Periodicals postage is paid at Denver, Colorado. POSTMASTER: Send address changes to:

$$
\begin{gathered}
\text { Love Publishing Company } \\
\text { Executive and Editorial Office } \\
\text { P.O. Box } 22353 \\
\text { Denver, Colorado } 80222 \\
\text { Telephone (303) } 757-2579
\end{gathered}
$$

Edward L. Meyen

University of Kansas

Richard J. Whelan

University of Kansas Medical Center
Stanley F. Love Publisher
Glenn A. Vergason Georgia State University

Thomas Love Associate Editor ualized and relevant learning objectives, and (d) being provided with the necessary support. Inclusion is not students with disabilities who (a) must spend every minute of the school day in general education classes, (b) never receive small-group or individualized instruction, and (c) are in general education classes to learn the core curriculum only.

"Full inclusion" is not addressed in this article because of the misconceptions about what it is and if it even exists separate from inclusion. Despite considerable rhetoric about full inclusion in the literature, in my opinion it often is misrepresented. Brown et al. (1991) note that nowhere in the literature do they find any professional who is saying that all students with all disabilities should always receive all of their instruction in general education classrooms.

\begin{abstract}
Members of the $100 \%$ club argue that only by spending every minute of each school day in regular education classrooms can true, whole, full, meaningful, and pure integration/inclusion be realized....The $100 \%$ club may not have a member. The authors do not know anyone, nor could they find a printed reference, that argues that all the students of concern should spend $100 \%$ of their school time in regular education classrooms. (p. 40)
\end{abstract}

The best academic práctices for inclusive classrooms are the methods that have the greatest desired impact in affective, psychomotor, and cognitive areas of academics for students with and without disabilities who are receiving most, if not all, of their differentiated, individualized, and appropriate learning, social, and instructional experiences together.

\section{PLACEMENT AND QUALITY INSTRUCTION}

The focus for inclusion has to emphasize both where things are happening and what types of practices are being used. For example, Kluwin and Moores (1985) noted that secondary students with hearing impairments who were integrated into general math classes were achieving more than matched counterparts at segregated schools. Yet the factors impacting higher achievement levels (e.g., higher expectations, exposure to greater quantities of demanding material, availability of individual support, and teachers trained in mathematics), they contended, could have been used in the segregated placement as well.

In a second study on the mathematics achievement of students with hearing impairments who were taught in different placements, Kluwin and Moores (1989) again found that the quality of the instruction, not the placement, was the main predictor of students' achievement. Although they did find, not 
surprisingly, that student background factors were a primary determinant of achievement and that student achievement was considered when deciding whether or not to mainstream a youngster, the placement the youngster received in and of itself was not connected to achievement. Specific characteristics of quality placement included a supportive teacher, regular and extensive reviews of the material, direct instruction, a positive climate, and requirements that students work.

Similarly, Fewell and Oelwein (1990) found that the amount of time children with developmental disabilities spent in mainstreamed preschool settings was not a factor alone that could impact better developmental outcomes. They concluded that the curriculum used and the quality of instruction had powerful effects on the children's acquisition of skills.

Hunt, Farron-Davis, Beckstead, Curtis, and Goetz (1994) evaluated the effects of placement on students with severe disabilities in general education versus special education classes. In some areas these researchers found significant differences favoring the students who were included (e.g., taught in an academic context, student with others, and student actively engaged). Other areas may not have attained significant results, but more positive results accrued to the students in inclusion. Students who were included initiated more interactions with peers without disabilities, and peers without disabilities initiated more interactions with the students with disabilities. In other areas, the findings showed significant differences favoring students in the special classes (student working alone, taught basic skill/critical activities).

Although one may argue that placement is less important than the quality of instruction, that argument cannot be made without the stipulation that some opportunities for quality instruction for some students simply are not available in segregated programs. Furthermore, segregation can occur within school buildings. Students need not attend a separate school to feel isolated. A person also can be isolated within a group setting, such that physical presence in a group may not meaningfully include a student.

In short, the content and quality of an educational program are critical factors to consider when determining which service delivery option is appropriate for any given youngster with a disability. Not surprisingly, instructional variables also have consistently emerged for general education students as having the potential to influence their achievement positively (Wang, Haertel, \& Walberg, 1993). Those researchers also found that instructional variables are correlated more powerfully with achievement than demographic, policy, and organizational variables. What may matter more than who the student is, or where he or she is from, or how the school system is organized, or what the educational policies are-is how good the instruction is for each student in the classroom.

\section{LAYING THE FOUNDATION FOR INCLUSION}

For inclusion to succeed, four foundational components are necessary upon which to "build" best practices. Foundational structures for inclusion are a shared vision, information about the change process, preparation, and ongoing support.

\section{Shared Vision}

Perhaps the most important start toward a shared vision that supports inclusion is that educators value and believe that students with and without disabilities should be together more in their learning and playing experiences at school. Misinformed preconceptions about inclusion and its effect on students can prohibit educators from envisioning an inclusive classroom with benefits for all students.

Research can provide information about students' progress in inclusive classrooms. For example, one concern about inclusion is the effect it will have on the academic achievement of students without disabilities. Parents, administrators, and general educators want to be satisfied that inclusion will not hold back other students. Several researchers have noted that academic achievement of typical students is not affected adversely under inclusion (e.g., Jenkins, Speltz, \& Odom, 1985; Liddiard, 1991). Other researchers have found significant gains for students without disabilities when inclusion occurs (e.g., Bear \& Procter, 1990).

\section{Change Process}

Planned educational changes typically have three stagesadoption or initiation, implementation, and incorporation - as a permanent feature of the system (Waugh \& Punch, 1987). Some educators resist changing toward inclusion because they lack information. In those instances, information must be provided. Other educators may be unclear about how to use new methods; consequently, training is necessary. Other educators, especially people who are skilled in using their current methods of instruction, may be reluctant to take the risks necessary to become skilled with new methods. Educators also need to feel actively involved in their school's change toward inclusion, and they need to participate in decisions made about changes. If educators are not involved in the development and implementation efforts, changes toward inclusion are less likely to be sustained. Yell, Deno, and Marston (1992) reported that teachers and administrators alike acknowledged the difficulty of initiating change into the educational system as one of three major obstacles to implementing curriculum-based measurement. When new procedures are introduced, teachers will resist and become anxious. 
They need to know their principal's or system's commitment to the change and support for teachers while they are learning and refining the use of new methods. Furthermore, teachers' feelings of discomfort as they learn how to use instructional techniques new to them should be expected (Joyce \& Weil, 1986), and corresponding support must be provided (Hord, Rutherford, Huling-Astin, \& Hall, 1987).

\section{Preparation and Ongoing Support}

Preparation and ongoing support are intertwined; one should not occur without the other. Joyce and Weil (1986) note that high-quality training provides excellent results.

\begin{abstract}
Important new learning involves pain, and teachers are well able to withstand the discomfort. In many quarters teachers have been undersold as learners simply because inadequate training has been provided. (p. 469)
\end{abstract}

Staff development may be the most critical part of inclusive special education services, according to Roahrig (1993). He recommends that the amount of money needed for staff development for inclusion, especially at start-up, may be equal to that of one staff member, but that having the teachers determine how the staff development money is to be used, rather than hiring one person who would try to meet all staff's needs, may be more effective.

Similarly, Wolery, Werts, Caldwell, Snyder, and Lisowski (1995) report that special and general educators involved in inclusion consistently rated personal training and support as high-need areas for implementing successful inclusion. Educators consistently stated a discrepancy between resources they perceived they needed and those actually available to them. Educators who rated themselves as more successful with inclusion, however, had a lower discrepancy between needed and available resources. Furthermore, all staff training should not occur prior to teachers' trying out inclusion; some training and support should occur after teachers have had a chance to work in an inclusive situation and can target new areas of individualized training for themselves based on specific challenges.

\section{BUILDING THE STRUCTURE FOR INCLUSION}

The structure for inclusion cannot weather the storm unless the foundation for inclusion has been firmly established. Changes toward inclusion are more likely to be sustained and institutionalized if the foundational components are sturdy. The 10 practices featured in Figure 1 and in the ensuing dis- cussion should not be taken as stand-alone entities but should be used in combination. Using only one practice well is not sufficient for best practice.

The 10 practices described next should be individualized for specific school systems, schools, and students so the content of the practices and the process for implementing the practices are appropriate. Individualization of the content and process components, however, cannot adapt too many elements of the practices without compromising the desired results. Leaving out some elements of a practice (for example, leaving out the immediate corrective feedback in classwide peer tutoring, or collecting data for curriculum-based assessment but not using the data to make instructional decisions) could jeopardize the practice's effectiveness. These practices are applicable to all students, but what teachers have to un-

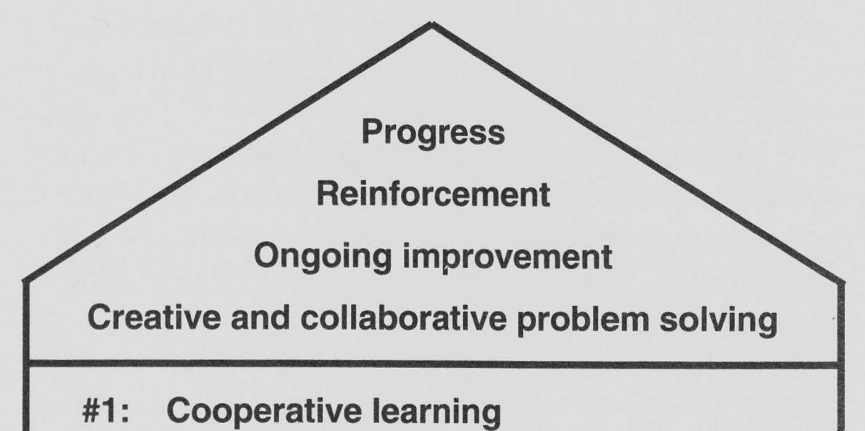

Cooperative learning

\#2: Strategy instruction

\#3: Differentiation

\#4: Self-determination

\#5: Explicit instruction

\#6: Curriculum-based assessment

\#7: Generalization techniques

\#8: Collaboration

\#9: Proactive behavior management

\#10: Peer supports

Shared vision Change process

Preparation Ongoing support 
derstand is that systematic implementation of key elements of a method (e.g., in strategy instruction, one key element is that students attain mastery level at certain stages) for students with disabilities who must have those elements may impact the method's effectiveness. Educators can-and shouldpersonalize implementation but not delete critical elements that contribute directly to the power of the method.

\section{Practice \#1: Cooperative Learning}

A variety of cooperative learning techniques have empirical support for students with and without disabilities, making these techniques a robust and powerful choice for educators to use in inclusive classrooms. Jenkins, Jewell, Leicester, O'Connor, Jenkins, and Troutner (1994) used Cooperative Integrated Reading and Composition (CIRC) with heterogeneous groups, along with cross-age and peer tutoring, phonics instruction for some learners, and in-class instructional support from specialists to investigate achievement in reading, spelling, and written expression for students with and without disabilities. Significant results were obtained for all groups of students on all academic measures.

The researchers note that, overall, the positive results indicate the power of cooperative learning techniques, but that some students still required direct intensive decoding instruction in addition to the cooperative learning techniques. An earlier study by these researchers (Jenkins, Jewell, Leicester, Jenkins, \& Troutner, 1991) did not produce significant results, and they suggested that the results may have been a result of eliminating key elements of CIRC (e.g., family involvement and comprehension exercises).

Kamps, Leonard, Potucek, and Garrison-Harrell (1995) used CIRC in third- and fifth-grade classrooms that included typical students and students with disabilities (autism, learning disabilities, and behavioral disorders). When cooperative learning alone was used in the third-grade classroom, students equaled or increased their quiz scores. Then the students were taught a social skills strategy (Vernon, Schumaker, \& Deshler, 1993) to promote cooperation and appropriate social interaction among the students. Students with and without disabilities increased their quiz scores even more when social skills instruction was combined with cooperative learning procedures. Individualizing reading levels was necessary for students with and without disabilities in the fifth-grade classroom; when all students were reading materials on their ability level, their performance improved.

Maheady, Sacca, and Harper (1988) used classwide peer tutoring (CWPT) in high school social studies classrooms where students with mild disabilities were included. Class- wide peer tutoring is a procedure by which all students tutor each other in a reciprocal arrangement, with each student serving the role as tutor and tutee. CWPT has had good success for increasing students' active participation in learning, which has enhanced their achievement positively (Delquadri, Greenwood, Whorton, Carta, \& Hall, 1986). Maheady and his colleagues found that CWPT virtually eliminated failing grades for all students, and that weekly test scores increased an average of 21 points.

Kamps, Barbetta, Leonard, and Delquadri (1994) investigated the use of CWPT in elementary classrooms that included fulltime students with autism. Classwide peer tutoring was an effective technique for increasing students' reading fluency and comprehension. Concurrently, the researchers found that social interactions during unstructured situations increased between the students with autism and their typical peers.

O'Connor and Jenkins (1993) noted that large differences sometimes were present in the task involvement of special education students and the amount and kind of help students extend to each other in cooperative learning structures. They investigated how elementary students with mild disabilities fared when cooperative learning was used. Effective cooperative group learning occurred for the students with disabilities when (a) students received appropriate help from a group member, (b) students contributed to the group effort, and (c) students completed the assigned task. O'Connor and Jenkins found that only $40 \%$ of the students with disabilities participated successfully in cooperative learning. They attribute this to two special education practices: (a) one-to-one adult-student interactions occurred during times when groups were working together; and (b) shortened assignments for students with disabilities appeared inappropriate when this resulted in students who seemed to have permission to stop working before the group work was completed.

In addition to the expected teacher behaviors prior to cooperative group work of teaching students how to work cooperatively, the teacher behaviors during cooperative learning also could influence cooperation. Teachers who monitored by interfering actively with the group's processing seemed to negate the idea that peers were expected to help each other. Teachers who lowered standards unnecessarily for individual students with disabilities also inhibited those students' full group membership. O'Connor and Jenkins (1993) suggest that cooperative learning as an inclusion strategy may not be successful if traditional special education modifications (e.g., one-to-one assistance, shortened assignments) are used, and that the status of all group members' contributions can be heightened by the way in which teachers praise and provide feedback to students. 


\section{Practice \#2: Strategy Instruction}

Strategy instruction is described here as an alternative format for working with students with disabilities that minimizes a tutorial, watered-down instructional format and maximizes more strategy-based formats. In essence, a strategic format directs educators' effort away from helping a student keep up with the day-to-day demands of content learning and redirects it toward enabling the student to learn strategies by which to keep up with those demands himself or herself.

For example, students with learning disabilities who learned a test-taking strategy scored higher on tests across content areas, which minimized the need for an adult to tutor them for each test (Hughes \& Schumaker, 1991). Park and GaylordRoss (1989) taught youngsters with mental retardation to use problem solving effectively to increase appropriate social interactions within their work settings. Schumaker and Deshler (1995) describe how the strategy instruction can enable students with disabilities to more independently think about, complete, and evaluate school tasks and assignments. Their research (see Deshler, Ellis, \& Lenz, 1996, for a comprehensive description of strategy research and methods) emphasizes eight stages for teachers to use in teaching strategies to students:

1. Pretest and obtain students' commitment to learn a strategy.

2. Describe the strategy steps (typically a mnemonic is used to help students remember the strategy steps; pictures or icons can be used with younger students or students with more severe cognitive disabilities).

3. Model the strategy by talking aloud about thinking while performing the strategy.

4. Verbally practice the strategy steps until the student has memorized the steps.

5. Use controlled practice and feedback. Students perform the strategy on ability-level, or easier, content; feedback is structured explicitly to move from teacher feedback to students' self-evaluation.

6. Use advanced practice and feedback. Students' perform the strategy on advanced, or grade-level, content with feedback that promotes students' self-evaluation.

7. Posttest (same format as pretest; allows direct comparisons of student's performance before and after use of the strategy).

8. Generalize. Although this is a formal, last stage, a focus throughout strategy instruction has been on where, when, why, and how the student can use the strategy.

The stages of instruction require students to master information at key junctures: verbal practice, controlled practice, advanced practice, and posttest. Students' active involvement in learning is required throughout, with an emphasis on students' acquiring and using more proactive behaviors such as goal-setting and self-evaluation.

Strain, Kohler, Storey, and Danko (1994) describe instructional stages and mastery requirements for preschool children with autism who learned to self-monitor their social interactions in school and at home. The three stages of initial instruction were (a) demonstration and modeling, (b) practice with the adult and other children, with adult feedback, and (c) practice with other children. During the final stage, the children had to demonstrate mastery performance (e.g., exchange four skills within a 10-minute period) before they could move to the next phases of self-monitoring.

Irvine, Erickson, Singer, and Stahlberg (1992) taught high school students with moderate to severe mental retardation to use picture schedules to initiate tasks at school. Later the students used the same self-management system to initiate tasks at home. When the students were being trained to use the selfmanagement system, mastery of $100 \%$ performance of the tasks without prompting was required. Although more time (all students mastered the required components after 5 consecutive days of practice) was necessary for the students to attain mastery, if the students could not perform the behaviors at a sufficient level during controlled situations, they could not be expected to perform the behaviors sufficiently in other situations.

Nelson, Smith, and Dodd (1992) found that the time duration of instructional sessions for students with learning disabilities who learned a summary skills strategy ranged from 43 minutes per session when initial instruction was occurring to 16 minutes per session for the final instructional session. A similar decrease in time was evident for the students when they used the strategy independently; independent reading sessions lasted 33 minutes initially and decreased to 16 minutes. The amount of time the students with disabilities need to achieve fluency and mastery of a strategy must be available, even if the rest of the class can acquire the elements of the strategy more quickly.

For teachers, the issue of competing demands is raised: If most of the class understands, what happens to the students who need more time to understand? What is the cost-benefit of proceeding with instruction when most of the students are ready to move on? What's the cost-benefit of proceeding with instruction when the few students who are not ready to move on also need to know the preceding information to move on and understand the new content? Mastering key pieces of information is necessary during instruction; students will not use the strategy independently if they do not achieve mastery (Scanlon, Deshler, \& Schumaker, 1996). 
A strategic approach to this dilemma is to minimize or eliminate special education instruction focusing solely on a tutorial approach that provides students with support to learn the day-to-day and week-to-week content (weren't most kids pulled for services like that?) and replaces that special education instruction with teaching robust strategic procedures in which the students learn how to make notecards (the FIRST Letter Mnemonic Strategy), how to understand more of what they read (the Paraphrasing Strategy), and how to decode multi-syllable words (the Word Identification Strategy). Whether the strategic instruction occurs in the general education classroom or in another setting should be less of an issue for inclusive classrooms than the issue of what students are learning how to do that they can use (a) independently, (b) in a variety of classes, and (c) to meet performance demands from a range of instructors.

The sessions for intensive and extensive strategic instruction may be a time when homogeneous groups of students who need to learn a strategy (the group may include students with disabilities, students who are at-risk for school failure, and so on) are formed to receive instruction that includes mastery and generalization of the instruction enabling them to more independently and correctly apply a set of rules, principles, or techniques across subjects, teachers, and materials. Although the concept of homogeneous groupings may seem to be in contrast to inclusive classrooms where heterogeneous groupings are emphasized, I contend they are not, depending on what is taught. If students are kept in heterogeneous groups all the time at the expense of a select subgroup of students learning strategies that will enable them to accomplish tasks across content areas more independently, that may be an inappropriate use of heterogeneous groups all the time.

Again, look at the cost-benefit for students. If they can spend one to two months of daily instruction learning a strategy they can use for the rest of the school year and the next school year and in out-of-school settings, too, what is the cost to them versus the benefit of the alternative of being tutored by someone who helps them pass each test and make the grade for each semester but doesn't teach them how to learn how to learn by themselves?

Stainback and Stainback (1990) emphasize the range of instructional possibilities available when teachers use differentiated techniques within heterogeneous groupings. They also acknowledge, however, that homogeneous groupings are appropriate at times.

Heterogeneous grouping should occur whenever possible. However, some students may need to be homogeneously grouped occasionally for instruction within a class or across classes according to their interests, needs, and capabilities. ... When such groupings occur, they should be based on the instructional needs of the students as they relate to the instructional focus of the class or grouping, rather than according to a categorical label such as retarded, normal, or gifted. Care also must be exercised to minimize such groupings to the greatest extent possible; but when they are used, they should be flexible, fluid, and short term to avoid the development of a tracking system and to allow students to move in, out, and across the groupings according to their needs and interest. (pp. 13, 14)

\section{Practice \#3: Differentiated Instruction}

A fair amount of evidence suggests that even when students with mild disabilities (e.g., learning disabilities) are taught by general educators who are receptive to their presence and who promote their progress, the instruction is not differentiated systematically to meet their individual needs (see Schumm \& Vaughn, 1995, for a research review). An issue becomes how much a general educator can differentiate his or her instruction. The factors underlying this issue include: (a) the quantity and quality of training experiences for that educator about student characteristics and effective practices for teaching a student with specific characteristics, (b) the extent to which an educator is willing to provide differentiated instruction, (c) the quantity and quality of support provided by a special educator who is knowledgeable about how to differentiate within general education curriculum and environments, and (d) how much educators know about how to effectively implement coteaching, co-planning, and problem-solving activities.

\section{Categories for Curriculum Differentiation}

Switlick (1997) and Giangreco, Cloninger, and Iverson (1993) describe categories of curriculum differentiation for students with disabilities. Their categories are expanded in Table 1 to include curriculum differentiation for students who are high achievers or gifted. For some differentiation areas, the content and concepts are the same. According to Switlick:

1. An accommodation is a modification to the delivery of instruction or method of student performance that does not significantly change the content or conceptual difficulty of the curriculum. A student who is completing fewer math problem-solving activities than the other students may be receiving an accommodation.

2. An adaptation is a modification to the delivery of instruction or method of student performance that changes the content or conceptual difficulty of the curriculum. An example of an adaptation is to have the student attempt to identify the main characters 
and setting of a story while the other students focus also on the plot, subplots, problem, and resolution.

3. Parallel instruction is a modification of the delivery of instruction or method of student performance that does not change the content area but does significantly change the conceptual difficulty of the curriculum. An example of parallel instruction is to have most students work on solving fraction problems and a student with moderate disabilities work on counting from 1 to 10 .

4. Overlapping instruction is a modification of the student performance expectations while all students take part in a shared activity or delivery of instruction that changes the content area and the conceptual difficulty of the curriculum. For example, in a cooperative group the students are tape-recording the rough draft of a play they are creating, and a student with physical and cognitive disabilities is using an adaptive switch to activate the recorder and working on following one-step directions and working on holding up his head for extended periods of time.

Table 2 provides explicit information about overlapping curriculum differentiation that can occur when a standard science curriculum (for typical students and students with mild disabilities) is used along with a functional life skills curriculum (for students with moderate to severe cognitive or developmental disabilities). All students are working together during science curriculum instruction, but the activities are differentiated for a student whose IEP goals stem from a functional life skills curriculum.

In the curriculum differentiation of Giangreco, Cloninger, and Iverson (1993):
1. The same curriculum is used with all students for whom no differentiation is needed.

2. In multilevel curriculum differentiation, all students work on the same content but some students may work on different levels of the content so the concepts may be different.

3. Overlapping curriculum is identical to Switlick's (1997) definition: Students are participating in the same activity, but a student may be working on different content and concepts altogether.

The version of curriculum differentiation shown in Table 1 expanded to include enrichment curriculum choices illustrates how teachers also differentiate for students who are high-achievers or are characterized as gifted. For general educators who already differentiate their instruction for students who are gifted, exposure to the three models in Table 1 provides more concrete information on differentiation that highlights what they are doing already for some groups of students, such as students who are gifted, and applies similar planning processes to include more groups of students (students at-risk, students with disabilities). Educators may find multiple intelligence theories and Dimensions of Learning frameworks to be useful guides in differentiating.

\section{IEPs to Guide Differentiation}

The content of IEPs, when they are developed by teams (including general educators, special educators, therapists, parents, and sometimes the student and the student's peers), can provide meaningful and valuable information. When IEP goals and objectives do provide qualitative and quantitative information, teachers can use them as a guide for determin-

\section{TABLE 1}

Differentiation of Curriculum for Students with Heterogeneous Learning Needs

\begin{tabular}{|c|c|c|c|c|}
\hline & Curriculum & & Content & Concept \\
\hline & & Enrichment & same & minor/major changes \\
\hline \multirow[t]{2}{*}{ Same } & & Standard & same & same \\
\hline & Accommodation & Strategic & same & same \\
\hline \multirow[t]{2}{*}{ Multilevel } & Adaptation & & same & minor changes \\
\hline & Parallel & & same & major changes \\
\hline Overlapping & Overlapping & & different & different \\
\hline
\end{tabular}




\section{TABLE 2}

\section{General Education Science and Functional Life Skills Curricula Overlapped}

\section{Science - Solutions}

\section{General Education Science Curriculum}

1. Observe and describe the properties of substances.

2. Observe, identify, and classify a solution or a liquid.

3. Observe, describe, and make inferences about the properties of liquids.

4. Observe and describe the interaction of solids and liquids.

5. Observe and describe the properties and interactions of substances.

\section{Observe and describe the effects of temperatures on liquids.}

\section{Life Skills Curriculum}

1. Prepare tray. Measure dry materials by using a measuring cup and spoon. Mix materials into water and stir with spoon. Identify clear and cloudy.

2. Participate with peers. Get tray of materials. Practice turn-taking and communicating whether substance is cloudy or clear.

3. Fill bottles with warm water. Count aloud the number of drops to go into the water as another student uses the dropper. Clear materials from table.

4. Participate with peers. Use stopwatch by pressing button to start and stop. Decide if tube is warm or cold.

5. Pass out trays. Have students stir the mixtures and communicate whether the crystals disappeared or stayed in the water. Stay within the group area.

6. Participate with peers. Stir substances into the water. Put materials away and clean area.

Source: From J. Hlass, J. Jorden, L. Lightner, \& D. Nagle (1995). Integration of life skills: General education curriculum and functional life skills curriculum (p. 51). Unpublished manuscript, Johns Hopkins University, Rockville, MD. Used by permission.

ing appropriate modifications within general education classroom routines, activities, and instruction. Figure 2 provides an example of how modifications are linked to the IEP. Giangreco, Dennis, Edelman, and Cloninger (1994), however, found, in their analysis of IEP content, that for students who were deaf-blind and attended general education classes either full-time or part-time, goals and objectives frequently are (a) broad, inconsistent, and poorly connected to general education contexts (e.g., "improve communication skills"), (b) listing content for staff (e.g., "reposition every hour") instead of content for the student, and (c) discipline-specific (e.g., "during therapy sessions ...." or "improve occupational therapy skills") instead of team-specific. When IEP content does not provide sufficient information that can guide differentiation decisions, the education team should expand on its content so the accomplishment of IEP goals and objectives are connected more explicitly to classroom instruction and activities.

\section{Higher-Order Thinking Skills}

Carnine (1991) presents research on curricular interventions for teaching higher-order thinking to students with and without learning disabilities. Students with learning disabilities who were taught in middle or high school science, math, or health classes achieved high scores (in some studies the differences were statistically significant) on critical content related to higher-order thinking skills (e.g., reasoning, understanding concepts, problem solving). He makes an important distinction between curricular interventions and instructional approaches by describing curricular interventions as academic content that is analyzed and communicated via curricular materials to promote understanding, transfer, and retention among all students. Carnine contends that to accomplish higher order thinking skills (such as concepts, rules, strategies, algorithms), the underlying processes have to be taught, and that the primary underlying theory for each type of skill 
Student Jason, a student with significant fine-motor difficulties

IEP Goal: To grasp and release objects from assisted to unassisted using real-life situations

Activity: Jason is a 2nd grade student with multiple disabilities, including significant fine-motor difficulties. His IEP includes occupational therapy goals. The occupational therapist has suggested that Jason be given opportunities to practice his newly acquired skills in real-life situations. Jason's class eats lunch in the cafeteria and moves through the line to purchase items such as milk, juice, snacks, and a complete lunch. As the students are moving through the lunch line, Jason will:

(a) choose appropriate food items and place these items on his tray

(b) have a peer buddy place the items on the tray for him

Which modification would you use in this situation?

Answer: (a) Jason's IEP goal is to grasp and release objects. Moving through the cafeteria line and grasping and releasing food items provides a real-life opportunity to practice the skill. In this case, Jason should get the items for himself. Support may be provided by a peer who has been given direct instruction in how to assist without picking the items up for Jason.

Source: From T. L. Bruff, J. C. Jacksits, L. A. Marchineck, \& K. D. Sandleitner (1996). Modifying instruction in diverse classrooms (p. 43). Unpublished manuscript, Johns Hopkins University, Rockville, MD. Used by permission.

\section{FIGURE 2}

\section{Linking Modifications to IEP Goals}

rests on the "sameness" features. He suggests that curricular content has to be organized around important samenesses as a means of teaching a larger variety of students with more heterogeneous learning patterns (such as students with mild disabilities and students at-risk for school failure).

\section{Multi-Age Groupings}

Some schools are beginning to use multi-age groupings in which students from more than one grade receive differentiated instruction (Miller, 1995). Multi-age groupings can assist with some of the logistical components of differentiated instruction because more than one teacher is available, and when homogeneous groupings for direct instruction occur, the teachers can vary student groupings across grade levels. For example, in a first/second multi-age group, both teachers form reading groups according to skill level, and, when they combine the grades, they avoid duplicating skill groups across grades and within one classroom.

Flexible groupings that change as needed also characterize multi-age grades; they create an atmosphere in which all stu- dents are grouped differently and regrouped when their performance indicates the need to regroup. All students receive individualized instruction based on their performance levels, so no students are singled out for individualized instruction. Although student groupings are homogeneous for some content, large-group instruction and heterogeneous groupingsin which cooperative learning activities are used and differentiated learning objectives are targeted-are clearly evident.

\section{Practice \#4: Self-determination}

Field and Hoffman (1994) propose a model for self-determination that includes five components for students:

1. Know yourself.

2. Value yourself.

3. Plan.

4. Act.

5. Learn.

Their definition of self-determination is the student's "ability to define and achieve goals based on a foundation of 
knowing and valuing oneself" (p. 164). Teaching students how to self-manage their behaviors can be used to promote self-determination. Self-management systems have enabled students with disabilities - across a wide range of ages, disability areas, severity levels, behaviors, and settings - to accomplish tasks and control behaviors more independently.

Moreover, when students with disabilities have been taught how to use self-management systems effectively, the onus for external behavior management systems shifts from needing an adult to manage and implement the external system to the student's being responsible for his or her own system of control. Effective inclusive classrooms do not just accommodate students with disabilities; methods that promote students' independence are evident. The range of possibilities for teaching students initial self-determination behaviors by using selfmanagement systems is wide. Some examples follow.

- Middle school students with behavior problems substantially increased appropriate peer interactions and decreased inappropriate interactions after learning selfevaluation techniques (Falk, Dunlap, \& Kern, 1996).

- Children with autism using self-management systems increased their appropriate play behaviors in unsupervised settings (Stahmer \& Schreibman, 1992).

- An adolescent with learning disabilities and behavior disorders used self-monitoring to improve his on-task behaviors and academic skills across special and general education settings (Prater, Hogan, \& Miller, 1992).

- Teenage students with autism were taught how to follow a schedule to make transitions in an after-school program; when students learned to make the transitions on their own, an adult no longer had to prompt them when it was time to move from one activity to another (Newman et al., 1995).

Van Reusen, Deshler, and Schumaker (1989) report that high school students with learning disabilities who were taught how to self-advocate during their individualized education program (IEP) conferences contributed important and relevant information to their educational plans. Furthermore, $86 \%$ of the goals on the IEPs for students who were taught how to participate effectively in their IEP conferences contained content they generated during the conference, in contrast to the IEPs for a control group of students, which contained only $13 \%$ content they identified.

\section{Practice \#5: Explicit Instruction}

Gersten, Carnine, and Woodward (1987) describe direct instruction as having six critical features:
1. An explicit step-by-step model.

2. Development of mastery at each step.

3. Process corrections for student errors.

4. Gradual fading from teacher-directed activities to students' independence.

5. Use of adequate, systematic practice with a range of examples.

6. Cumulative review of newly learned concepts.

Direct instruction teaching procedures have enabled students with and without disabilities to learn content. More recently, however, educators have been exploring the use of constructivism, which is less structured and teacher-directed than direct instruction. Constructivist teaching and learning has been emphasized particularly in general education classrooms, leading to questions about how well that type of teaching results in efficient learning for students with, in particular, mild disabilities (Harris \& Graham, 1996). Rosenshine and Stevens (1986) suggest that direct instruction procedures may be more effective when the content is more structured (e.g., vocabulary, grammar, factual information, general rules) than when content is less structured (e.g., appreciation, analysis of literature, problem solving in specific content areas, discussion of social issues).

What is emerging today regarding direct instruction versus constructivism is that students with disabilities (a) benefit most from direct instruction procedures, (b) can learn within a constructivist framework when teaching procedures are more explicit initially, and (c) should not be taught using an "eitheror" perspective; both are needed to promote effective, efficient, and independent learning. Most students with disabilities will not thrive in a classroom setting that does not provide elements of explicit instruction that include demonstration, guided practice, independent practice, active learner involvement, and meaningful connections of content to real life.

Mercer, Jordan, and Miller (1996) describe effective math instruction for diverse learners that promotes students' active involvement in and self-regulation of learning. They note that a teacher's sole reliance on a traditional constructivist approach for math instruction (i.e., minimal teacher support, emphasis on discovery, eventual self-regulation) is not sufficient for learners who need more teacher support and explicit instruction. They note that a constructivistic classroom places many demands on learners-demands that many learners with learning disabilities, for example, have trouble meeting without explicit instruction from an expert-the teacher.

Their steps for explicit instruction are:

1. Introduce the lesson.

2. Describe and model the skill or strategy. 
3. Use scaffolding to guide practice and interactions.

4. Conduct independent practice to mastery.

5. Provide feedback.

6. Teach for generalization and transfer.

Mercer et al. (1996) note that implicit instruction (e.g., when the teacher models the skills or strategy) also occurs throughout explicit instruction as a complement to the directed instruction. Discovery of rules and procedures is more directed and controlled so errors are not learned or practiced.

\section{Practice \#6: Curriculum-Based Assessment}

Curriculum-based measurements (CBM-repeated measures on long-term goals) and curriculum-based assessment (CBA-repeated measures on long-term goals or short-term objectives) can indicate to teachers that their teaching methods are resulting in desirable achievement gains for individuals or groups of students (Marston, 1988). Teachers who collect data frequently (e.g., before, during, and after instruction) using direct observation techniques (e.g., the number of math problems the student can solve correctly, how well the student verbalizes the correct application of problem-solving methods) and use those data to make instructional decisions (is cooperative learning working? is more practice required?) have students who accomplish more and higher academic goals (Wesson, Skiba, Sevcik, King, \& Deno, 1984).

Fuchs and Fuchs (1986) found an effect size of .70 on student achievement when teachers gathered and used systematically gathered formative evaluation measures. When teachers used data-evaluation rules (i.e., analyze student data at regular intervals and make instructional changes based on data) the effect size was higher than when teachers used judgment alone. When teachers graphed data, the visual stimulus of the graphed data resulted in higher effect sizes than when teachers simply recorded their data. Although the time needed for teachers to collect data and use it to make instructional decisions can be a barrier to using curriculum-based assessment, the benefits that promote student achievement and actively involve the students often can make it worth their while.

Gersten, Keating, and Irvin (1995) state that an assessment is not valid for informing instruction unless there is evidence that the assessment information is used by teachers as intended, and that it results in improved learning. One could extrapolate from their view, then, that teachers who use assessment only to give a grade or to fill in a score are not using valid assessments. Assessments must be used to improve learning for students, and they cannot be used to improve learning for students unless they also are used to guide teach- ers' decision-making during learning, not solely or primarily at the end of the unit of instruction.

Fuchs, Fuchs, Hamlett, Phillips, and Bentz (1994) investigated the use of curriculum-based measurement in general education classrooms where students with learning disabilities were included. They found that the students in classrooms where CBM that included specific instructional recommendations was used achieved greater gains. The CBM general educators used a computer program to facilitate implementation of CBM decision making and to involve the students in reading and interpreting their graphs and skills profiles. General educators in this study seemed to need specific recommendations, provided via the computer software program, to use the CBM student data for planning instruction.

Several researchers have looked at different assessment models, including curriculum-based assessment, as described above, and performance assessments based on the curriculum, and measured students' performance in heterogeneous settings. Dalton, Tivnan, Riley, Rawson, and Dias (1995) found that students with learning disabilities and students who were low-achieving and average-high achieving obtained significantly higher scores on a performance-based science assessment than when paper-and-pencil assessments were used. Those authors also note the value of diversifying assessment formats (for example, using multiple intelligence pathways) for all students so the assessment format does not prevent students from demonstrating their knowledge and application of skills and concepts learned.

When developing and using varied assessment formats, teachers must remain focused on what the learning goals are. Having demonstrated a procedure may tell you that a person can demonstrate the procedure but may not tell you why certain choices were made during the procedure and let you know that the student understands the underlying principles and concepts of that procedure-the learning goals.

Although facts tests and paper-and-pencil products receive criticism for not inducing higher-order thinking skills or being relevant/meaningful measures of content, teachers also must realize that the same criticisms can arise with performancebased or authentic assessments if they are not constructed carefully to measure critical thinking. For example, in one inclusive classroom of fourth graders (students with physical disabilities, cognitive disabilities, and typical students) who were learning geometry, the students were required to draw a picture of their bedrooms to illustrate the geometry patterns. Although the teacher may have considered this an authentic and performance-based assessment, some students could draw a picture of their bedroom but not identify the geometric patterns. Without also assessing the identity of the geometric pat- 
terns (which was the learning goal), the illustration itself does not demonstrate the intended learning outcome.

Another teacher who assigned projects based on multiple intelligence theory for the heterogeneous groups in her classroom (composed of typical students and students with serious emotional disturbance) realized midway through the unit that although students were enjoying the varied choices in projects and getting excited about making different projects, she had omitted the learning goals or standards that each project was supposed to accomplish. Some teachers have found grading rubrics useful to inform students at the beginning of instruction about standards that will be used in evaluating projects.

Tindal, Rebar, Nolet, and McCollum (1995) studied varied instructional outcomes for students with learning disabilities in content classes. They emphasize the impact of curriculum structure on assessment and instruction by noting that higherorder learning (which they claim can be measured in traditional and nontraditional formats) can be achieved for heterogeneous groups of students when a unit is reorganized to focus on concepts and principles. Students with and without learning disabilities whose teachers had reorganized their content and used content enhancements (e.g., graphic organizers) when delivering instruction scored comparably on assessment formats (that included selection and production responses), a range of knowledge forms (including facts, concepts, principles), and higher-order thinking skills (such as prediction, evaluation, and application). The relative standing of students with learning disabilities in some of the areas assessed (problem-solving essay) changed in that the students moved from well below the class average to very near it. The researchers further note that the ensuing instruction must be preceded by curricula shifting from a compilation of facts to be memorized to rearranged, reprioritized, and relevant concepts and principles.

When general educators use instructional methods with heterogeneous groups of learners, to look only at the group's average score is not sufficient. Disaggregated scores from heterogeneous groups can provide the teacher with more specific information about how each group, or representative students from each group, is performing. By looking at the performance of the varied groups within the classroom, the teacher can make more informed decisions about how well the instruction is working. In one method, called HALO (Deshler, 1992; King-Sears \& Cummings, 1996), scores on assessments are separated for four groups of students within a classroom: High achievers or gifted students, Average achievers or typical students, Low achievers or students atrisk for school failure, and $O$ ther students or students with disabilities. The progress for students' scores across HALO categories should indicate that all groups are progressing.

\section{Practice \#7: Generalization Techniques}

Imperative in educators' knowledge of effective inclusive methods is educators' knowledge of where they are taking the whole class, as well as where they are taking each individual student, in any given curriculum. What students will be learning, why they are learning that information, and how that information applies in real-world living must be established at a macro level before selecting any method to use at a micro level.

Mundschenk and Sasso (1995) prepared typical peers to interact with students with autism during free-play sessions. As part of the training, the peers were involved in generating situations and social interaction behaviors instead of using situations and behaviors designed by the researchers. By using the peers' existing repertoire of behaviors and by eliciting their perspectives on situations, the researchers conjectured that more natural behaviors and opportunities for interacting with students with autism, rather than more artificial situations and behaviors, may have occurred in their study. During their baseline measures, Mundschenk and Sasso confirmed that peer interactions with the students with autism did not occur naturally; the peers needed training on how to interact. Consequently, the researchers were interested in how many typical peers had to be trained on interactions before generalization would occur. After analyzing data in which up to five peers were trained for interactions, the researchers concluded that only when three trained peers interacted within the free-play sessions did generalized initiations and responses from typical peers and the students with autism occur. Although they caution against assuming that three is a magic number, their results are instructive in that training all typical peers may not be necessary before interaction behaviors begin to have a ripple effect across a group of students.

Cole and Meyer (1991) studied students with severe disabilities in integrated and segregated environments. They found that the students in integrated environments scored significantly higher in four areas of social functioning. The integrated students initiated more contacts, obtained more cues, were more accepting of assistance, and indicated their preferences more than their counterparts in segregated environments. Furthermore, students in segregated environments tended to regress instead of making gains in several social functioning areas. The researchers conjectured that skills taught for community participation in segregated schools may not have offered the variety of natural opportunities available in integrated schools to allow those skills to generalize. In this situation, the placement does seem to matter as a pivotal part of the instruction; generalization environments 
must be readily available for generalization to occur.

Antia, Kreimeyer, and Eldredge (1993) studied the social interaction of young children with hearing impairments in integrated settings, and they compared two treatments conducted in small groups (four to six children). One group was taught a more structured social skills approach, and the other group was provided an integrated-activities intervention. Both groups were similar in increasing their interactions with peers of different hearing status, although more frequent interactions occurred for same-status peers than with differentstatus peers. Children in the integrated-activities approach, however, increased their interactions with each other significantly as a result of the intervention. The authors surmised that the integrated-activities approach was more amenable to generalization because the intervention occurred during typical play activities.

One also could surmise that the social skills approach was solely classroom-based without explicit instruction within the real environment. That is, the "controlled" environment of the classroom may have to be followed by the "advanced" or "real" environment of the playground as part of the social skills instruction. This situation could be akin to a traditional approach from special educators or related service personnel who note the discrepancy between what students with disabilities can do well within self-contained or controlled environments/materials/instructions, but the students' behaviors do not shift easily into the real environments. Teaching for generalization throughout instruction and as an explicit component of instruction continues to be necessary (Ellis, Lenz, \& Sabornie, 1987; Haring \& Liberty, 1990); if the generalization components are not evident then the chances for generalization are minimized greatly.

Not only do adults need to design and deliver generalization methods during instruction, but the students also need to be involved actively in the rationale for learning and using the specific content in other places, with other people, and during different circumstances. Connell, Carta, and Baer (1993) taught preschoolers with developmental delays how to self-assess and recruit teacher praise. When the children were taught how to both self-assess their behaviors and recruit reinforcement from adults, their active engagement during other classroom situations (outside the targeted situation) increased.

Students with disabilities who are taught how to use selfmanagement procedures have used those systems more successfully to generalize their behaviors to other situations, settings, and people. Self-management (note that self-management also is used as a self-determination behavior) systems have enabled students with disabilities to (a) reduce disruptive classroom behaviors in special and general edu- cation classrooms (Rhode, Morgan, \& Young, 1983), (b) interact appropriately in unsupervised settings (Pierce \& Schreibman, 1994), and (c) increase appropriate social interactions in school and at home (Strain, Kohler, Storey, \& Danko, 1994).

\section{Practice \#8: Collaboration}

With a multitude of methods to choose from when implementing inclusion in general education settings (Bradley, King-Sears, \& Switlick, 1997; Thousand \& Villa, 1990; Udvari-Solner \& Thousand, 1995), educators grapple with selecting effective and appropriate methods for individual students with disabilities, juggling the use of those methods in heterogeneous classrooms where other students may or may not benefit from the same methods, and monitoring students' progress to ensure that any method used is having the desired effects. The most effective inclusive methods are determined, implemented, and monitored by a team of people (including educators, parents, peers, other school personnel, and community agency personnel) who are collaborating. Warger and Pugach (1996) suggest that collaboration among educators toward inclusion starts with a careful and critical examination of the general education curriculum when including students with mild disabilities. The focus then moves from a more traditional emphasis on the student as the problem to a more progressive emphasis on the learning environment and how the demands of that environment affect all the students, not just a student with a learning problem.

Utley (1993) suggests a variety of ways by which to facilitate and measure teaming to promote inclusive services. Her endorsement of transdisciplinary teams, in which personnel provide direct and indirect services, is shared by many other professionals to accomplish inclusion (e.g., Downing \& Bailey, 1990; Gallivan-Fenlon, 1994). Reed (1993) noted further that more comprehensive and coordinated recommendations can be done in less time when assessment teams use a transdisciplinary approach. A transdisciplinary approach to teaming is one in which each professional's unique skills, typically delivered to the student directly from that professional, are shared and transferred across people. Thus, the speech/ language pathologist would be working within a transdisciplinary model to actively share information and skills with general educators, special educators, parents, and others; therapy is promoted throughout the youngster's day. In a transdisciplinary approach, a speech/language therapist would not cease providing direct services to the youngster, but the therapist would work more closely with other team 
members toward integrating the service across the day. A therapist also might deliver direct services within the context of the classroom environment instead of a more isolated therapy session. Co-teaching often is the form of delivery (Walther-Thomas, Bryant, \& Land, 1996). Key components of a transdisciplinary approach are collaboration, cooperation, and coordination.

Effective inclusive classrooms feature collaboration not only among adults but also among students. Rainforth (1992) describes how general educators who had included students with severe disabilities in elementary classrooms learned more about disabilities both from adult teammates and from the typical students. One reason the students were able to inform the teachers was because this model for inclusion used an incremental approach beginning with kindergarten instead of the whole school. By the time the group of students reached first and second grades, their cohesiveness as a community of learners seemed well developed and their knowledge about how to include their peer with severe, profound, or multiple disabilities surpassed their teacher's knowledge. One teacher commented, "The kids are growing up learning sign language. The kids are growing up seeing things people used to call grotesque as commonplace" (p. 10).

Teachers involved in this program taught about disabilities in their classrooms both as a formal part of the curriculum and incidentally, as appropriate. Including the students with disabilities was not always easy and stress-free, but the teachers were not alone. Students also were active participants in collaborative problem-solving activities in which they partnered with adults to adapt activities. Several teachers found that involving the class in problem solving was more logical and natural because the students often saw the need for adaptations first, had a vested interest in solutions, and were influential in implementing solutions. Another teacher commented that students developed more creative, and sometimes easier, adaptations than the teachers did.

Effective inclusive classrooms are nurtured by collaboration both from students and from adults in the school. Many professionals, however, are realizing the magnitude of issues (e.g., violence, dysfunctional home life) that children today bring to the classroom that seem insurmountable even given the best and most school resources. While acknowledging the degree of success he and his colleagues attained using differentiated, cooperative methods in elementary classrooms, Jenkins et al. (1994) also despair that some of the students needed more intensive services than are available currently in public education. To better address the needs of some youth with (and without) disabilities, collaboration must extend beyond school personnel to include community agency personnel within a transdisciplinary model (Dikel, Bailey, \& Sanders, 1994).

\section{Practice \#9: Proactive Behavior Management}

Carpenter, Musy, and King-Sears (1997) synthesized research on effective behavior management methods and found that interventions occur at three levels within a school: schoolwide, classroom, and individual. Proactive behavior management interventions are those that most effectively prevent problems from occurring. These interventions are instructional in orientation, promote a positive learning climate, are made up of responsive and dynamic interventions, and benefit from teachers' experiencing collegial interactions. For example, features of an effective schoolwide discipline policy include (a) a proactive approach to managing behavior that is consistent across the school, (b) clear and consistent school rules, (c) frequent and positive communication with families, (d) collegial teams that support individual teachers and students, and (e) training and involvement that ensure a safe, secure school environment.

O'Neill, Williams, Sprague, Horner, and Albin (1993) found success in providing support for teachers working with students with severe problem behaviors (such as biting, kicking, hitting) by using a Teacher Support System. Case studies of seven students revealed that four of the students with moderate to severe mental retardation and/or autism were maintained in an inclusive placement after their teachers received assistance from members of the Teacher Support System. For the three students who were placed in more self-contained environments, the authors stated that staff turnover and inconsistent and ongoing program implementation were factors. The Teacher Support System's function was to provide technical assistance that went beyond consultation. Teachers needed initial training and assistance as they began to implement interventions, followed by ongoing support (including assistance in monitoring the effects of the interventions).

Flicek, Olsen, Chivers, and Kaufman (1996) report that students with emotional or behavioral disorders who were integrated into a combination fourth- and fifth-grade classroom increased their scores on a behavior checklist completed by their teachers such that by the end of the year in the Combined Classroom Model, their behaviors were within the average range. Furthermore, they (typical peers and peers with learning disabilities) maintained their academic standings and report card grades (decreases were not evident arising from their enrollment in this model). In addition, they achieved significant gains in mathematics applications. Techniques used in the Combined Classroom Model included (a) coteaching, (b) weekly social skill lessons, and (c) behavior 
management level systems.

\section{Practice \#10: Peer Supports and Friendships}

Staub, Schwartz, Gallucci, and Peck (1994) used observations, videotaped samples, and interviews to determine the effects of inclusion of four students with moderate and severe disabilities on four of their peers without disabilities. Two of the three classrooms the students were in used multi-age groupings and cooperative learning. In particular, friendships between the students with disabilities and their peers without disabilities were studied. What emerged were four descriptions of friendships, ranging from a helping relationship to more of a typical friendship. All of the friendships were developed outside of a tutorial or instructional context and were initiated by the students themselves, not by an adult.

The researchers noted that once the friendships were established, the students without disabilities began to take on more of a caretaker role in three of the four friendships. To place a subjective descriptor on this role for students without disabilities is difficult. In some instances the role of caretaker can be good, and in other instances the role of caretaker may inhibit the student with a disability from becoming more independent (Does a peer always prompt the student with a disability to complete classroom routines instead of the student completing those routines on his or her own when capable of doing so?).

Hunt, Alwell, Goetz, and Sailor (1990) found that high school students with severe disabilities who were taught to increase their conversation skills (both initiating and maintaining a conversation), with instruction occurring across a variety of school settings and with several general education students serving as communication partners, the high school students with severe disabilities engaged in social interactions independently and decreased their inappropriate behaviors. The students with severe disabilities used communication books, photographs, and line drawings to assist them and their peers with dialogue.

Brady, Martin, Williams, and Burta (1991) investigated the influence of social play activities with nondisabled peers on the motor and social responses of students with severe, multiple disabilities. The peers were taught how to interact with the students during brief training sessions (15 minutes) across a week (total of 1 hour of initial training for the peers). The researchers concluded that the peers increased their social behavior toward the students. Also, targeted motor behaviors (e.g., reaching, holding head upright) increased for each of the students with severe, multiple disabilities. Interestingly, for the student whose motor behavior included reaching, the left arm was targeted because the student had preferred that arm over time as a result of limitations on his right side; however, during peer interactions the student's motor behavior increased with both arms. Several adults noted that this was the first time they had seen him reaching with his right arm and were surprised that he had that ability-one that seemed to "unlock" as a result of peer interactions.

Kamps, Leonard, Vernon, Dugan, and Delquadri (1992) found that first-grade students without disabilities and their peers with autism could be taught social skills effectively within small groups in which social skills were targeted for all students, not just the students with autism. The types of social skills that were instructed-participating in conversations, giving and receiving compliments, taking turns and sharing, helping others and asking for help, and including others in activities - were appropriate for all of the students. Furthermore, Kamps et al. determined that focusing instruction on fewer social skills with more practice activities was more efficient than teaching more skills without adequate practice. This concept of "less is more" seemed to benefit not only the students without disabilities but also the students with autism by providing more concrete demonstrations of appropriate behaviors.

Haring, Breen, Pitts-Conway, Lee, and Gaylord-Ross (1987) found that peer tutoring or a special friends program between typical high school students and students with autism, severe mental retardation, moderate mental retardation, and deaf/blindness was successful in increasing the social interactions between typical students and their peers with a variety of moderate to severe disabilities. A control group of typical peers who were not involved in either the peer tutoring or the special friends program experiences did not increase their social interactions. This research lends some credence to the argument that simply placing students in physical proximity may not alone induce interactions; that some type of training program has to occur; and that the type of training program (e.g., special friend, peer buddy) may not matter as much as that training does occur.

Ferguson et al. (1992) describe integration efforts in which physical proximity was a goal resulting in the creation of "bubble kids" or "velcro kids." They note that physical integration can be a "step on the way" to inclusion, and that true inclusion has the potential to flourish in the context of "reinvented" schools in which people develop "flexible, creative learning environments that include and are responsive to a full range of human diversity, including disability, race, culture, learning style, intelligence, personal preference, socioeconomic class, and family and community priorities" (p. 36).

Haring and Breen (1992) recruited junior high students to participate as part of a social network for two students with 
moderate and severe disabilities. The students with disabilities received the majority of their educational services in separate classrooms, but they were mainstreamed during lunch and transitions between classes. Teachers reported that during these unstructured parts of the day, the students had few appropriate interactions with their peers without disabilities. Typical peers were recruited to form a social network, taught how to interact (including the use of a self-evaluation scale), and assigned a specific time during the day to interact with the students with disabilities. Concurrently, one student with disabilities was taught to self-monitor his behaviors while interacting by pressing a wrist counter for each appropriate social response. By teaching the student with disabilities to selfmonitor his interactions, the student himself became even more actively involved in the intervention versus being a passive recipient of an intervention.

Bimonthly network meetings were held for problem-solving and progress-reporting discussions. As a result of the social network, appropriate responding for one student with disabilities increased during the unstructured situations from $20 \%$ of the available opportunities (during baseline) to $38 \%$ (when students from the social network prompted and initiated interactions) to $81 \%$ (when the student used self-monitoring). Maintenance checks one and two months later indicated an ongoing high frequency of interactions. For the other student, appropriate responding skills increased to $78 \%$ (selfmonitoring and maintenance phases were not implemented for this student).

Haring and Breen (1992) note that forming and supporting the social networks seems a more effective, efficient, and natural way for students with disabilities to learn how to participate in nonstructured contexts. Furthermore, direct adult support was not necessary to initiate and maintain these interactions. The intervention seemed to rely more on peercontrolled and peer-generated procedures (with the adult as the facilitator) than on adult-controlled procedures.

Peer supports and friendships may be more readily available when youngsters with disabilities participate in community activities, such as recreation programs. Bernabe and Block (1994) found that modifying rules for a girls softball league to include a girl with moderate to severe disabilities did not affect her teammates' or other teams' performance. The girl's batting average, under the modified rule that she could use a batting tee, was not significantly different from the mean batting average for the rest of her team. The student also seemed to be well received by her teammates, which may not be surprising in this situation because she already was included in her neighborhood middle school. Her on-task behavior improved so that by the end of the season, she needed less frequent reminders to direct her attention to relevant aspects of the game.

\section{MAKING SURE THE INCLUSIVE STRUCTURE STANDS}

Once teachers have received initial training in best practices for inclusion, one should not presume that those practices will be implemented correctly, systematically, and painlessly without additional support and technical assistance. Progress for students and adults should be evident, reinforcement for all should be available, ongoing improvement and refinement should be a goal, and creative, collaborative problem solving should continue. Waugh and Punch (1987) note that teachers want to know if their investment in new methods is likely to yield a greater return on factors such as student achievement and personal satisfaction. The progress of students - with and without disabilities - has to be evident. If teachers perceive that the personal cost of planning and implementing new methods is too great and results in little student progress, new methods may not be continued.

To feel comfortable all the way through change toward inclusion, even for people who want the change and are acting as the change agents, is not possible. Who has dieted and lost weight and enjoyed not eating their favorite foods? What makes the pain of dieting worth it? The benefit is derived when one looks better and feels healthier. What helps a person to stay on a diet despite the pain? Comments from others that reinforce dieting efforts and encourage one to "stick with it." What administrators and other change agents (the change agents for inclusion do not necessarily have to be the administrator; effective change efforts involve change agents from different levels and sources including teachers, other staff members, parents, and students) have to realize is that (a) change will not be easy and smooth, (b) support must be provided, and (c) support needs and methods will vary.

Scanlon, Deshler, and Schumaker (1996) note that secondary content teachers who learned and used strategic instruction designed to enhance learning for students with mild disabilities within heterogeneous settings were successful in using the methods but did not experience consistent significant academic gains for all students with disabilities. The teachers reported that, although they would have liked to have had more time to emphasize the strategic processes in their teaching and they realized how the instruction would benefit their students with and without disabilities, they perceived that they also faced competing demands for their time in class related to content coverage. 
Gersten, Morvant, and Brengelman (1995) note that general educators are constantly balancing priorities. Increased success for students with disabilities is only one of many priorities competing for teachers' time. Similarly, Gelzheiser and Meyers (1996) found that general educators seem well aware of the benefits to individual students with disabilities when those students are included, but that more persuasive evidence for inclusion includes advantages for the teacher and the classroom as a whole. The cost of such instruction for some students has to be offset by the benefits for all students.

Greenwood et al. (1993) found that using a computer program designed to assist teachers as a "consultant" when they were implementing ClassWide Peer Tutoring programs was effective in prompting the teachers (a) when students were not being challenged enough or they were receiving material too difficult for their level, and (b) to examine varied reasons about why the method may not be being implemented correctly, such as too few sessions scheduled. The computer program was developed to help ensure fidelity of treatment, provide problem solving, and promote support. In a series of studies, Greenwood and his colleagues found that for teachers who still were working on getting the basic elements of ClassWide Peer Tutoring in place, the computer program typically responded with those elements and addressed differential group achievement. For teachers who had those basic elements in place, however, the computer program was able to focus on problems and concerns for individual students. What the computer program was able to do was to identify implementation problems and offer advice for addressing those problems.

Fuchs, Fuchs, and Hamlett (1994) also note how computer software can be used with curriculum-based measurement to enhance the effectiveness and efficiency with which teachers implement and use CBM. In particular, the use of technology was instrumental in complementing teachers' efforts to individualize instruction and make decisions on teaching based on students' data. When teachers are able to use such technology, the logistical barriers surrounding individualization can be minimized.

Gersten, Morvant, and Brengelman (1995) studied peer coaching as a way to bring research-based teaching practices into general education classrooms to improve the quality of reading instruction for students with learning disabilities. Over 3 years of working with general and special educators, they reached several conclusions that coincide with those of others who have studied the change process (Hall \& Loucks, 1978; Joyce \& Weil, 1986; Loucks-Horsley \& Roody, 1990; Wisniewski \& Alper, 1994):
1. Changed practices are implemented in an "up-anddown" pattern that reflect how hard it is to alter current practice and how tough it can be to integrate new patterns into a teacher's repertoire.

2. New practices, although they may seem uncomplicated for one professional, require extensive time to master. Joyce and Weil (1986) recommend 12 to 14 applications of a new practice to enable a person to feel more comfortable with that practice.

3. An implicit, yet unintended, message when teachers are told to use new practices is that they have been doing things "wrong" and they feel as if they are being evaluated, not assisted or coached, when they are trying something new. Ongoing refinement, continuous improvement, and risk taking have to be encouraged and supported.

4. Teachers report that what can offset the uncomfortable feelings of trying something new are the performance gains they see from their students as a result of the new practice.

5. Teachers have to be informed about the "why" of the new practice, not just the "what" and "how." The rationale is especially important for teachers to understand theory and research premises that support new practices.

What content should be taught in an educational program that effectively includes students with a range of disability labels and severity? What makes a quality program for those youngsters? And how can the appropriate content and quality instruction be delivered for them when different content and other types of quality instruction also have to be delivered to typical students in a general education setting? Educators who are creative and collaborative problem solvers are finding unique, practical, and effective ways to make inclusion work for them and their students (Thousand, Villa, \& Nevin, 1994). Rarely can one person accomplish inclusion alone, and never can inclusion be successful using only one method. Just as a synergy occurs when people work together, so does a synergy occur when students with disabilities are exposed to a variety of effective practices.

The best academic practices for inclusion are instructional techniques that promote achievement, independence, and interdependence of individual students- with and without disabilities-within settings that include students who have a range of learning needs as a learning community. Heterogeneous groupings often are used, but not without individualization, differentiation, and heterogeneous techniques. The heterogeneously grouped settings should be (a) attained for 
the majority, if not all, of the school day, (b) individualized such that each student-with and without disabilitiesachieves academically and socially, and (c) monitored so achievement gains are evident. Sometimes those practices may be delivered in small groups, frequently in large groups, and sometimes one-to-one instruction. What's most imporiant for the students is the quality of instruction. What's most important about the instruction is that the content target meaningful and relevant learning. What's most important for teachers is the training and support that promote their comfort with effective inclusive practices. What's most important for the students is that they have multiple opportunities throughout their school careers to learn, work, and play with peers who are different from them, and that those differences are valued, accepted, and appreciated.

Consider this: How many practitioners, who today are responsible for developing, validating, and implementing inclusive practices, were schooled themselves in environments rich in such diversity? The prospect is exciting that tomorrow's practitioners-who may be receiving instruction right now in classrooms that promote acceptance and achievement by students with a wide range of learning needs-will be refining today's best practices in light of their own experiences. At no point can any of us rest on what we know now. Our challenge is to continually develop and refine techniques that work for each student within school classroom contexts and more accurately mirror the work and community contexts within which today's students will be living tomorrow.

\section{REFERENCES}

Antia, S. D., Kreimeyer, K. H., \& Eldredge, N. (1993). Promoting social interaction between young children with hearing impairments and their peers. Exceptional Children, 60, 262-275.

Baker, E. T. (1994). Meta-analytic evidence for non-inclusive educational practices: Does educational research support current practice for special needs students? Unpublished dissertation submitted to Temple University Graduate Board.

Bernabe, E. A., \& Block, M. E. (1994). Modifying rules of a regular girls softball league to facilitate the inclusion of a child with severe disabilities. Journal of the Association for Persons with Severe Handicaps, 19, 24-31.

Bear, G. G., \& Proctor, W. A. (1990). Impact of a full-time integrated program on the achievement of nonhandicapped and mildly handicapped children. Exceptionality, 1, 227-238.

Bradley, D. F., King-Sears, M. E., \& Switlick, D. M. (1997). Teaching students in inclusive settings: From theory to practice. Needham Heights, MA: Allyn \& Bacon.

Brady, M. P., Martin, S., Williams, R. E., \& Burta, M. (1991). The effects of fifth graders' socially directed behavior on motor and social responses of children with severe multiple handicaps.
Research in Developmental Disabilities, 12, 1-16.

Brown, L., Schwarz, P., Udvari-Solner, A., Kampschroer, E. F., Johnson, F., Jorgensen, J., \& Gruenewald, L. (1991). How much time should students with severe intellectual disabilities spend in regular classrooms and elsewhere? Journal of the Association for Persons with Severe Handicaps, 16, 39-47.

Bruff, T. L., Jacksits, J. C., Marchineck, L. A., \& Sandleitner, K. D. (1996). Modifying instruction in diverse classrooms. Unpublished manuscript at Johns Hopkins University, Rockville MD.

Carnine, D. (1991). Curricular interventions for teaching higher order thinking to all students: Introduction to the special series. Journal of Learning Disabilities, 24, 261-269.

Carpenter, S. L., Musy, T. L., \& King-Sears, M. E. (1997). Behavior management methods. In D. F. Bradley, M. E. King-Sears, \& D. M. Switlick, Teaching students in inclusive settings: From theory to practice (pp. 322-364). Needham Heights, MA: Allyn \& Bacon.

Cole, D. A., \& Meyer, L. H. (1991). Social integration and severe disabilities: A longitudinal analysis of child outcomes. Journal of Special Education, 25, 340-351.

Connell, M. C., Carta, J. J., \& Baer, D. M. (1993). Programming generalization of in-class transition skills: Teaching preschoolers with developmental delays to self-assess and recruit contingent teacher praise. Journal of Applied Behavior Analysis, 26, 345-352.

Dalton, B., Tinvan, T., Riley, M. K., Rawson, P., \& Dias, D. (1995) Revealing Competence: Fourth-grade students with and without learning disabilities show what they know on paper-andpencil and hands-on performance assessments. Learning Disabilities Research and Practice, 10, 198-214.

Delquadri, J., Greenwood, C. R., Whorton, D., Carta, J. J., \& Hall, R. V. (1986). Classwide peer tutoring. Exceptional Children, 52, 535-542.

Deshler, D. D. (1992). Lecture delivered to graduate students in an inclusion master's program at Johns Hopkins University, Rockville, MD.

Deshler, D. D., Ellis, E. S., \& Lenz, B. K. (1996). Teaching adolescents with learning disabilities: Strategies and methods $(2 \mathrm{~d}$ ed.). Denver: Love Publishing.

Dikel, W., Bailey, J., \& Sanders, D. (1994). Community mental health support services in a special education setting. Behavioral Disorders, 20, 69-75.

Downing, J., \& Bailey, B. R. (1990). Sharing the responsibility: Using a transdisciplinary team approach to enhance the learning of students with severe disabilities. Journal of Educational \& Psychological Consultation, 1, 259-278.

Ellis, E. S., Lenz, B. K., \& Sabornie, E. J. (1987). Generalization and adaptation of learning strategies to natural environments: Part 2: Research into practice. Remedial \& Special Education, 8(2), 6-23.

Falk, G. D., Dunlap, G., \& Kern, L. (1996). An analysis of selfevaluation and videotape feedback for improving the peer interactions of students with externalizing and internalizing be- 
havioral problems. Behavioral Disorders, 21, 261-276.

Ferguson, D. L., Willis, C., Boles, S., Jeanchild, L., Holliday, L., Meyer, G., Rivers, E., \& Zitek, M. (1992). Regular class participation system (RCPS): A final report. (ERIC Document Reproduction Service No. ED 359741 )

Fewell, R. R., \& Oelwein, P. L. (1990). The relationship between time in integrated environments and developmental gains in young children with special needs. Topics in Early Childhood Special Education, 10, 104-116.

Field, S., \& Hoffman, A. (1994). Development of a model for selfdetermination. Career Development of Exceptional Individuals, 17, 159-169.

Fisher, J. B., Schumaker, J. B., \& Deshler, D. D. (1995). Searching for validated inclusive practices: A review of the literature. Focus on Exceptional Children, 28(4), 1-20.

Flicek, M., Olsen, C., Chivers, R., \& Kaufman, C. J. (1996). The combined classroom model for serving elementary students with and without behavioral disorders. Behavioral Disorders, 21, 241-248.

Fuchs, L. S., \& Fuchs, D. (1986). Effects of systematic formative evaluation: A meta-analysis. Exceptional Children, 53, 199-208.

Fuchs, L. S., Fuchs, D., \& Hamlett, C. L. (1994). Strengthening the connection between assessment and instructional planning with expert systems. Exceptional Children, 61, 138-146.

Fuchs, L. S., Fuchs, D., Hamlett, C. L., Phillips, N. B., \& Bentz, J. (1994). Classwide curriculum-based measurement: Helping general educators meet the challenge of student diversity. Exceptional Children, 60, 518-537.

Gallivan-Fenlon, A. (1994). Integrated transdisciplinary teams. Teaching Exceptional Children, 26(3), 16-20.

Gelzheiser, L. M., \& Meyers, J. (1996). Classroom teachers' views of pull-in programs. Exceptionality, 6, 81-98.

Gersten, R., Carnine, D., \& Woodward, J. (1987). Direct instruction research: The third decade. Remedial \& Special Education, $8(6), 48-56$.

Gersten, R., Keating, T., \& Irvin, L. K. (1995). The burden of proof: Validity as improvement of instructional practice. Exceptional Children, 61, 510-519.

Gersten, R., Morvant, M., \& Brengelman, S. (1995). Close to the classroom is close to the bone: Coaching as a means to translate research into classroom practice. Exceptional Children, 62, 52-66.

Giangreco, M. R., Cloninger, C. J., \& Iverson, V. S. (1993). Choosing options and accommodations for children. Baltimore: Paul H. Brookes.

Giangreco, M. F., Dennis, R. E., Edelman, S. W., \& Cloninger, C. J. (1994). Dressing your IEPs for the general education climate. Remedial \& Special Education, 15, 288-296.

Greenwood, C. R., Finney, R., Terry, B., Arreaga-Mayer, C., Carta, J. J., Delquadri, J., Walker, D., Innocenti, M., Lignugaris-Kraft, J., Harper, G. F., \& Clifton, R. (1993). Monitoring, improving, and maintaining quality implementation of the classwide peer tutoring program using behavioral and computer technology. Education \& Treatment of Children, 16, 19-47.

Hall, G. E., \& Loucks, S. F. (1978). Teacher concerns as a basis for facilitating and personalizing staff development. Teachers College Record, 80(1), 36-53.

Haring, T. G., \& Breen, C. G. (1992). A peer-mediated social network intervention to enhance the social integration of persons with moderate and severe disabilities. Journal of Applied Behavior Analysis, 25, 319-333.

Haring, T. G., Breen, C., Pitts-Conway, V., Lee, M., \& GaylordRoss, R. (1987). Adolescent peer tutoring and special friend experiences. Journal of the Association for Persons with Severe Handicaps, 12, 280-286.

Haring, T. G., \& Liberty, K. A. (1990). Matching strategies with performance in facilitating generalization. Focus on Exceptional Children, 22(8), 1-16.

Harris, K. R., \& Graham, S. (1996). Constructivism and students with special needs: Issues in the classroom. Learning Disabilities Research \& Practice, 11, 134-137.

Hlass, J., Jorden, J., Lightner, L., \& Nagle, D. (1995). Integration of life skills: General education curriculum and functional life skills curriculum. Unpublished manuscript, Johns Hopkins University, Rockville, MD.

Hord, S. M., Rutherford, W. L., Huling-Austin, L., \& Hall, G. E. (1987). Taking charge of change. Alexandria, VA: Association for Supervision \& Curriculum Development.

Hughes, C., \& Schumaker, J. B. (1991). Test-taking strategy instruction for adolescents with learning disabilities. Exceptionality, 2, 205-221.

Hunt, P., Alwell, M., Goetz, L., \& Sailor, W. (1990). Generalized effects of conversation skill training. Journal of the Association for Persons with Severe Handicaps, 15, 250-260.

Hunt, P., Farron-Davis, F., Beckstead, S., Curtis, D., \& Goetz, L. (1994). Evaluating the effects of placement of students with severe disabilities in general education versus special classes. Journal of the Association for Persons with Severe Handicaps, 19, 200-214.

Irvine, A. B., Erickson, A. M., Singer, G. H. S., \& Stahlberg, D. (1992). A coordinated program to transfer self-management skills from school to home. Education \& Training in Mental Retardation, 27, 241-254.

Jenkins, J. R., Jewell, M., Leicester, N., Jenkins, L. M., \& Troutner, N. M. (1991). Development of a school building model for educating students with handicaps and at-risk students in general education classrooms. Journal of Learning Disabilities, 24, 311-320.

Jenkins, J. R., Jewell, M., Leicester, N., O’Connor, R. E., Jenkins, L. M., \& Troutner, N. M. (1994). Accommodations for individual differences without classroom ability groups: An experiment in school restructuring. Exceptional Children, 60, 344-358.

Jenkins, J. R., Speltz, M. L., \& Odom, S. L. (1985). Integrating normal and handicapped preschoolers: Effects on child develop- 
ment and social integration. Exceptional Children, 52, 7-17. Joyce, B., \& Weil, M. (1986). How to learn a teaching repertoire. Models of teaching (pp. 469-489). Boston: Allyn \& Bacon. Kamps, D. M., Barbetta, P. M., Leonard, B. R., \& Delquadri, J. (1994). Classwide peer tutoring: An integration strategy to improve reading skills and promote peer interactions among students with autism and general education peers. Journal of Applied Behavior Analysis, 27, 49-61.

Kamps, D. M., Leonard, B., Potucek, J., \& Garrison-Harrell, L. (1995). Cooperative learning groups in reading: An integration strategy for students with autism and general classroom peers. Behavioral Disorders, 21, 89-109.

Kamps, D. M., Leonard, B. R., Vernon, S., Dugan, E. P., \& Delquadri, J. (1992). Teaching social skills to students with autism to increase peer interactions in an integrated first-grade classroom. Journal of Applied Behavior Analysis, 25, 281-288.

King-Sears, M. E., \& Cummings, C. S. (1996). Inclusive practices of classroom teachers. Remedial \& Special Education, 17, $217-225$.

Kluwin, T. N., \& Moores, D. F. (1985). The effects of integration on the mathematics achievement of hearing impaired adolescents. Exceptional Children, 52, 153-160.

Kluwin, T. N., \& Moores, D. F. (1989). Mathematics achievement of hearing impaired adolescents in different placements. Exceptional Children, 55, 327-335.

Liddiard, H. J. (1991). The academic achievement of second, third, and fourth grade regular education students involved in special education programs. Unpublished thesis at Eastern Michigan University. (ERIC Document Reproduction Service No. ED 377 963)

Loucks-Horsley, S., \& Roody, D. S. (1990). Using what is known about change to inform the regular education initiative. Remedial \& Special Education, 11(3), 51-56.

Maheady, L., Sacca, M. K., \& Harper, G. F. (1988). Classwide peer tutoring with mildly handicapped high school students. Exceptional Children, 55, 52-59.

Marston, D. (1988). The effectiveness of special education: A time series analysis of reading performance in regular and special education settings. Journal of Special Education, 21(4), 13-26.

Mercer, C. D., Jordan, L., \& Miller, S. P. (1996). Constructivistic math instruction for diverse learners. Learning Disabilities Research \& Practice, 11, 147-156.

Miller, W. (1995). Are multi-age grouping practices a missing link in the educational reform debate? NASSP Bulletin, 79(568), 27-32.

Mundschenk, N. A., \& Sasso, G. M. (1995). Assessing sufficient social exemplars for students with autism. Behavioral Disorders, $21,62-78$.

Nelson, J. R., Smith, D. J., \& Dodd, J. M. (1992). The effects of teaching a summary skills strategy to students identified as learning disabled on their comprehension of science text. Education \& Treatment of Children, 15, 228-243.

Newman, B., Buffington, D. M., O’Grady, M. A., McDonald, M. E.,
Poulson, C. L., \& Hemmes, N. S. (1995). Self-management of schedule following in three teenagers with autism. Behavioral Disorders, 20, 190-196.

O’Connor, R. E., \& Jenkins, J. R. (1993). Cooperative learning as an inclusion strategy: The experience of children with disabilities. (ERIC Document Reproduction Services No. ED 360 778)

O’Neill, R., Williams, R., Sprague, J. R., Horner, R. H., \& Albin, R. W. (1993). Providing support for teachers working with students with severe problem behaviors: A model for providing consulting support within school districts. Education \& Treatment of Children, 16(1), 66-89.

Park, H., \& Gaylord-Ross, R. (1989). A problem-solving approach to social skills training in employment settings with mentally retarded youth. Journal of Applied Behavior Analysis, 22, 373-380.

Pierce, K. L., \& Schreibman, L. (1994). Teaching daily living skills to children with autism in unsupervised settings through pictorial self-management. Journal of Applied Behavior Analysis, 27, 471-481.

Prater, M. A., Hogan, S., \& Miller, S. R. (1992). Using self-monitoring to improve on-task behavior and academic skills of an adolescent with mild handicaps across special and regular education settings. Education \& Treatment of Children, 15, 43-55.

Rainforth, B. (1992). The effects of full inclusion on regular education teachers. (ERIC Document Reproduction Services No. ED $365059)$

Reed, M. L. (1993). The Revised Arena Format (RAF): Adaptations of transdisciplinary evaluation procedures for young preschool children. Education \& Treatment of Children, 16, 198-205.

Rhode, G., Morgan, D. P., \& Young, K. R. (1983). Generalization and maintenance of treatment gains of behaviorally handicapped students from resource rooms to regular classrooms using self-evaluation procedures. Journal of Applied Behavior Analysis, 16, 171-188.

Roahrig, P. L. (1993). Special education inclusion: Fiscal analysis of Clark County schools inclusion site grant. (ERIC Document Reproduction Services No. ED 373 528)

Rosenshine, B., \& Stevens, R. (1986). Teaching functions. In M. C. Wittrock (Ed.), Handbook of research on teaching (pp. 376-391). New York: Macmillan.

Scanlon, D., Deshler, D. D., \& Schumaker, J. B. (1996). Can a strategy be taught and learned in secondary inclusive classrooms? Learning Disabilities Research \& Practice, 11, 41-57.

Schumaker, J. B., \& Deshler, D. D. (1995). Secondary classes can be inclusive, too. Educational Leadership, 52(4), 50-51.

Schumm, J. S., \& Vaughn, S. (1995). Getting ready for inclusion: Is the stage set? Learning Disabilities Research \& Practice, 10, 169-179.

Sobsey, D., \& Dreimanis, M. (1993). Integration outcomes: Theoretical models and empirical investigations. Developmental Disabilities Bulletin, 21(1), 1-14.

Stahmer, A. C., \& Schreibman, L. (1992). Teaching children with 
autism appropriate play in unsupervised environments using a self-management treatment package. Journal of Applied Behavior Analysis, 25, 447-459.

Staub, D., Schwartz, I. S., Gallucci, C., \& Peck, C. A. (1994). Four portraits of friendship at an inclusive school. Journal of the Association for Persons with Severe Handicaps, 19, 314-325.

Stainback, W., \& Stainback, S. (Eds.). (1990). Support networks for inclusive schooling. Baltimore: Paul $\mathrm{H}$. Brookes.

Strain, P. S., Kohler, F. W., Storey, K., \& Danko, C. D. (1994). Teaching preschoolers with autism to self-monitor their social interactions: An analysis of results in home and school settings. Journal of Emotional \& Behavioral Disorders, 2, 78-88.

Switlick, D. M. (1997). Curriculum modifications and adaptations. In D. F. Bradley, M. E. King-Sears, \& D. M. Switlick, Teaching students in inclusive settings: From theory to practice (pp. 225-251). Needham Heights, MA: Allyn \& Bacon.

Tindal, G., Rebar, M., Nolet, V., \& McCollum, S. (1995). Understanding instructional outcome options for students with special needs in content classes. Learning Disabilities Research \& Practice, 10, 72-84.

Thousand, J. S., \& Villa, R. A. (1990). Strategies for educating learners with severe disabilities within their local home schools and communities. Focus on Exceptional Children, 23(3), 1-24.

Thousand, J. S., Villa, R. A., \& Nevin, A. (Eds.). (1994). Creativity and collaborative learning: A practical guide to empowering students and teachers. Baltimore: Paul H. Brookes.

Udvari-Solner, A., \& Thousand, J. S. (1995). Promising practices that foster inclusive education. In R. A. Villa \& J. S. Thousand (Eds.), Creating an inclusive school (pp. 87-109). Alexandria, VA: Association for Supervision \& Curriculum Development.

Utley, B. L. (1993). Facilitating and measuring the team process within more inclusive educational settings. In L. Kupper (Ed.), National symposium on effective communication for children and youth with severe disabilities (pp. 55-77). (ERIC Document Reproduction Services No. ED 359 695)

Van Reusen, A. K., Deshler, D. D., \& Schumaker, J. B. (1989). Effects of a student participation strategy in facilitating the in- volvement of adolescents with learning disabilities in the individualized educational program planning process. Learning Disabilities: A Multidisciplinary Journal, 1(2), 23-34.

Vernon, D. S., Schumaker, J. B., \& Deshler, D. D. (1993). The SCORE skills: Social skills for cooperative groups. Lawrence, KS: Edge Enterprises.

Walther-Thomas, C., Bryant, M., \& Land, S. (1996). Planning for effective co-teaching: The key to successful inclusion. Remedial \& Special Education, 17, 255-265.

Wang, M. C., Haertel, G. D., \& Walberg, H. J. (1993). Toward a knowledge base for school learning. Review of Educational Research, 63, 249-294.

Warger, C. D., \& Pugach, M. C. (1996). Curriculum considerations in an inclusive environment. Focus on Exceptional Children, 28(8), 1-12.

Waugh, R. F., \& Punch, K. F. (1987). Teacher receptivity to systemwide change in the implementation stage. Review of Educational Research, 57, 237-254.

Wesson, C., Skiba, R., Sevcik, B., King, R. P., \& Deno, S. (1984). The effects of technically adequate instructional data on achievement. Remedial \& Special Education, 5(5), 17-22.

Wisniewski, L., \& Alper, S. (1994). Including students with severe disabilities in general education settings. Remedial \& Special Education, 15(1), 4-13.

Wolery, M., Werts, M. G., Caldwell, N. K., Snyder, E. D., \& Lisowski, L. (1995). Experienced teachers' perceptions of resources and supports for inclusion. Education \& Training in Mental Retardation \& Developmental Disabilities, 30, 15-26.

Yell, M. L. (1995). Least restrictive environment, inclusion, and students with disabilities: A legal analysis. Journal of Special Education, 28, 389-404.

Yell, M. L., Deno, S. L., \& Marston, D. B. (1992). Barriers to implementing curriculum-based measurement. Diagnostique, 18 , 99-112.

York, J., Doyle, M. B., \& Kronberg, R. (1992). A curriculum development process for inclusive classrooms. Focus on Exceptional Children 25(4), 1-16. 


\title{
STRATEGIES FOR TEACHING EXCEPTIONAL CHILDREN IN INCLUSIVE SETTINGS
}

\author{
Edward L. Meyen, University of Kansas \\ Glenn A. Vergason, Georgia State University \\ Richard J. Whelan, University of Kansas - Medical Center
}

This new book is highly practical and translates research into classroom practice that works. You'll find new ideas to help teachers develop effective instructional strategies. It includes curriculum, assessment, classroom management, and collaboration.

It is designed for both general education students and those preparing to be special educators. The text will help teachers to work with special needs students in the inclusive classroom. All of the important issues and trends are addressed in this new comprehensive text. It is brightly written and engages the reader.

\section{Special Features:}

- Empirically based instructional strategies for effective teaching

- Provides procedures for conflict resolution and classroom control

- Shows how to work with students with complex health care needs

- Covers the relationship between consultation and collaborative problem solving

- Addresses all of the cutting edge assessment issues

- Discusses strategies for teaching thinking skills to students with mild disabilities

- Examines new approaches to inclusion

- Written by experts in the field

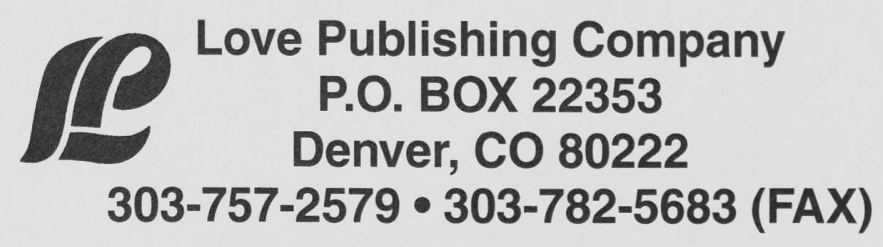




\section{Professional update}

\section{National Association of School Psychologists}

April 1-5, 1997

Anaheim Hilton Hotel

Anaheim, California

Contact: National Association of School Psychologists 4340 East West Highway

Suite 402

Bethesda, MD 20814

\section{International Association of Special Education}

August 3-7, 1997

Cape Town, South Africa

Contact: Helmi Owens

School of Education

Pacific Lutheran University

Tacoma, WA 98447

(206) 535-7292

\section{Council for Exceptional Children}

April 9-13, 1997

Annual Conference

Salt Lake City, Utah

Contact: Council for Exceptional Children 1920 Association Drive

Reston, VA 22091

\section{The China - U.S. Conference on Education}

July 9-13, 1997

Beijing, People's Republic of China

This will be the largest gathering of Chinese and American educators ever assembled. Conference cost is $\$ 2,850$ for a nineday Conference Program Package including international airfare, meals, lodging, conference fees, cultural and historic sites in Beijing. Also available are study programs to other cities, a demonstration learning center, and school partnerships. For detailed information on the Conference contact:

Global Interactions, Inc.

Department GC-97

14 West Cheryl Drive

Phoenix, AZ 85021

Telephone: 602-943-3922

Fax: 602-943-4458

\section{PERMISSIONS AND COPYRIGHT}

All rights are reserved. No part of this publication may be reproduced, photocopied, faxed, stored in a retrieval system, or transmitted, in any form or by any means, electronic, mechanical, recording or otherwise, without the prior written permission of the publisher.
Back issues are available for sale. Reproduction requires permission and payment of fees. It is illegal and a violation of federal copyright law to reproduce this publication without permission. Direct all inquiries to the permissions editor. 